\title{
Perspectives and Implications of Japanese Language Teachers on the Cooperative Learning Implemented in The Classrooms Conducted at Senior High Schools in Makassar
}

\author{
Imelda $^{1}$, Margariet M.Lappia ${ }^{2}$ \\ \{imelda@unhas.ac.id ${ }^{1}$, margariet@unhas.ac.id $\left.{ }^{2}\right\}$ \\ Japanese Department, Faculty of Sciences and Cultures, Hasanuddin University ${ }^{1}$, History \\ Department, Faculty of Sciences and Cultures, Hasanuddin University ${ }^{2}$
}

\begin{abstract}
The purpose of this research is to figure out the perspectives of Japanese language teachers and the implementation of cooperative learning conducted in the classroom at five Private Senior High Schools in Makassar. The research found that the teachers haven't clearly understood the perspectives and implications of cooperative learning as thosearenot commonly used at their schools. The teachers, which are considered as the participants in this research, tend to usegroup discussionsin traditional perspectives which highly focuson the grammatical patterns, while the cooperative learning is consideredas one scientific approach in the 2013 curriculum. Group discussion activities with authentic and attractive topicsmay encourage the students' motivation as reflected from the 2013 curriculum to the recently implemented learning activities in their teachings. In the other words, the implementation of group discussionsin the classroom is still conventional in which the teachers still become the centers of attention in learning the grammatical patterns. The teachers have not completely understood the roles, procedures andstrategiesused in the effective group discussionsof modern perspectives to reach the goals regarding to theimplementation of cooperativelearning.
\end{abstract}

Keywords: Perspective, implication, conventional, cooperative learning.

\section{Introduction}

As the demands of communicative learning and teaching across the globe, including Indonesiahave rapidly increased, teaching paradigmsshould also gradually be shifted. Many language teachershave been thinking about the importance of those paradigms and trying to encourage students to learn without considering more onthe rigid grammatical rules in meeting the paradigms. Thus, students are expected to be able to use the language naturally and communicatively as the native speakers do.It means that the language should be authentic.

In order to improve the teaching methods and in respond to the shiftingparadigmsrelated to the recently global teaching trends, Indonesia has changed its curriculum several times. Indonesia has implemented the Competence Based Curriculum, with some revisions. As the government thought that it was no longer relevant, KTSP emerged to replace the previousone andeventually came to the most recent one called the 2013 curriculum which might also end by the year of 2017. Indonesiangovernment has been striving in such a way to socialize the latest 
curriculum through teacher trainings that the teachers may use appropriate teaching methods and implement them in the classrooms across the nation up to the end of the program, which was, in 2017. Of course the names of curriculum have changed, but it is not necessary to change those required by anyonewho are directly involvedin this curriculum to change the previous traditional paradigm to show and implement the spirit of 2013 curriculum. The new curriculum and paradigm require many changes in term of syllabus and lesson plans, learning styles, teaching methods, classroom activities, scoring systems and students' evaluation.

Japanese is one foreign language taught at fivePrivate Senior High Schools in Makassar. Japanese language is regarded as one subject atSenior High Schoolswhich status have changed into "lintasminat" meaningthat students may choose one, no matterwhat majorthe students are taking. It is implied that Japanese language should be able to compete with the other foreign languages, such as Chinese, German, Arabic, and English. Due to the conditions, the government has been collaborating with The Japan Foundation in Jakarta since 2013 and simultaneously introduces and trains new teaching methods to the teachers, particularly in Makassar that the teachers become more competent in various aspects, such as in Japanese language mastery, pedagogic, and sociolinguistic competence. Those are prepared in order to enablethe Japanese Language program to be implemented based on 2013 curriculum.

Teachers play important roles to create the atmospheres for communicative teaching and learning as well as to facilitatestudents as the centers of classroom activities, expose themwith various experiencesand build their characters in the classroom [1]. Philosophy or moral values included in the curriculum are relevant with the cooperative learning discussed in this paper [2] Although cooperative learning practices in Japanese language class seem to be difficult to be implemented in Makassarcontext, it is quite interesting to investigate and figureout the teachers' teaching perspectives and implementation at Senior High Schools.

The scopes of this research coverJapanese language teachers' perspectiveson cooperative learning at five Private Senior High Schools in Makassar and how the teachers implement the cooperative learning in the classrooms. The purposes of the researchareto analyze 1) the Japanese language teachers' perspectiveson 2013 Curriculum at Senior High Schools in Makassar and 2) how the teachers implement 2013 Curriculum in the classrooms.

Richards, Plat and Platt (1992) in Byrammention that cooperative learning is not something in communicative-based teaching (Bayram, 2013) although both cooperative and communicative teaching are naturally and inherently taught in foreign language teaching [3],[4]. It is impliedthat the teaching paradigms have shifted from the traditional teaching approaches which are based on rote learning or grammatical rules to the communicative language teaching approacheswhich requirethe target languagesto be appropriately or authentically used as the native speakers do, instead of focusing on monotonous activities based on grammar rules.

Many articles and definitions on cooperative learning have been published, yet the authorsonly select some appropriate definitions regarding to the efficiency. cooperative learning is defined as "An instructional arrangement in which small group or teams of students work together to achieve team success in a manner that promotes the students' responsibility for their own listening as well as the learning of others" [5]. Kagan's definition is in accordance with that made by Mercer \& Mercer's thatcooperativelearning is commonly implemented by the students to share information [6]. Azizinezhadmentions that many researchers have made various definitions on cooperative learning, yet some are more accurately described thatcooperative learning is a system in teaching and a technique in learning which urge the students to be active. Students play important roles in the classroom instead of passively listen to the teachers without involving in various activities [10]. Akdemirmentions that cooperative learning is a learning activity with a small group of students working togetherand supporting 
each other in order to complete their tasks [7].Thus, the researchers conclude that based on the definitions mentioned above, cooperative learning is a small group discussion containing approximately five members who share information and work together. They are tolerant and responsible as each member plays important roles to design their learning strategies in order to achieve the goals.

Wina Sanjaya states that there are fouraspects incooperative learning: 1) Members in a group. Students may form a group based on various reasons, such as interest, talent, background, ability, or mixed to achieve their learning objectives.2) Rules in a group. Each member engaged in a group should have an agreement on what they should do while making inside or outside interactions of the group. It means that as learnersthey shouldmake various contributions to their own group according to the assigned tasks, yet during activities they also need to make interactions with the othersor teachers in the classroom. 3) Effort to learn. Each member in a group has to work hard by improving their skills, such as sharing information, experiences, or ideas in such a way that all effortsare used to activate the previous background knowledge and new information. 4) Goal. They must achieve the goal through what established by the group involving planning and evaluation. It is expected that through the established goal, each member may understand the target they should achieve in their learning [8]. According to WinaSanjaya, a group discussion usually consists of 4-6 members whose academic background knowledge, genders, and ethnicityare normally different (heterogeneous). The cooperative learningcovers the followings: 1) Positive interdependentclassroomconditionsare created by the teacherswhichencouragethe students tohelp each other while doing several tasks and findingvarious resources, as well as playing different roles, yet they still require supports from others; 2) They make student-student or student-teacher face to face interactions; 3) Individual accountability shows subjectmasteryindividually learned in which the teacher showsthe assessment results to all members to make sure that each comprehends the lessons; 4) The learning process is in a group and its membersmay be identified through some activity stagesto ensure that theymay more effectively make contributions according to the goals in a group;5) Social skills-based activities may activate their knowledge to communicate and interactbetter. Leadership, decision makingandmanagementof conflicts are integrated parts within a group work thatthe teacher has to motivate the students on how to usetheir skills in learning [9]. Wina Sanjaya states that one of cooperative learning characteristics emphasizes on the processes of working together, not merely considering students' mastery onsubject materials or academic skills.

Wina Sanjaya states that cooperative learning may be explained based on some aspects, such as motivation, social, cognitive development, and cognitive elaboration perspectives [8]. WinaSanjayadescribes the cooperative learning procedures as follows: 1) the teachers has important roles to explain the subject materialguidelineswhich may be delivered through lecturing, brain storming, and question-answer session. Teachersmay use teaching media to createmore attractive learning processes; 2) the teachers askthe students to form groups regardless to their heterogeneous backgrounds. In terms of academic skills, one group might contain a member withadequately high skill level, two with average skill level, and otherswith below the average skill level. However, the formation may help the teachers to improve the one with the lowest skill level with the help of the other three through interaction in the group. 3) The assessment of cooperative learning may be conducted through tests or quizzes, both individually and in a group. The final scores of each student are obtained from individual and group scores which are divided by two. All members in a group get the same scores, while the individual score may vary since it is on the basis of each member performance. 4) A group showing the best performance mayobtain acknowledgement and be given awards to improve 
the winning group members'learning motivation which may also encouragethe other groups to work better [8]. It is implied that cooperative learning is one step takento makethe students become more active and not dominatedby the teachers' instructions all the time. The teachers do not keep lecturing, but also encourage the students to share information through interactions and team works. In addition, teachersshould be able to create learning atmospheres that students are motivated and encourage each other to accomplish the tasks in a group.

Researches on cooperative learning have been conducted many times in some parts of the globe including the one conducted by Masoud Azizinehad entitled "Application of cooperative learning in EFL classes to enhance the students' language learning”, analyzingthe impacts of cooperative learning in English as Second Language (ESL) learners' performance and motivation as well as how they reach their academic achievement due to their various backgrounds in a group [10]. The other research on motivation conducted by Hui Zhou entitled “Enhancing Non-English Major's EFL Motivation through Cooperative Learning”, shows how English lecturers at universities in China consider students' motivation as something important. This is due to the facts that there are few systematic ways implemented to increase L2 students' motivation [10]. Cooperative learning Method is also employed by engineering students in Malaysia to improve language learning motivation and it is considered significant to improve creativity and skills by working together within a small group to solve complicated tasks or exercises [11]. The implementation of cooperative learning method does not only stop at the bachelor degree but is also effective to be implemented at the early-age education and elementary school of one university in Spain. The researchers implement this method in linguistic learning (L1) and literary competence [11].

The research on cooperating learning above is based on the university's background which focuses on both English learning and non linguistic learning. Thus, the authors think that teachers have important roles in implementing this method in the class. The research on trainings of cooperative learning focusing on teachers has been conducted.This research categorizes the assessment on teachers as the research respondents joining the training of cooperative learning based on gender, education level, age, knowledge [12].

The authors argue that learning activities contained within 2013 curriculum is still new for almost all Japanese Language Teachers in Makassar because the curriculum has just been implemented in 2017. Thus, the authors consider that it is important to figure out and analyzethe perspective and implementation of cooperative learning in Japanese language learning in several private schools in Makassarwhich have already implemented 2013 curriculum.

\section{Method}

In this research, the authorsemploy adescriptive-qualitative method by interviewing the teachers as the research participants to obtainthe learning perspective on cooperative and its implementation in the Japanese language classrooms.

\subsection{Research Background and Participants}

This research uses a purposive sampling regarding tothe effectiveselecting participants. The research is conducted atfive Private Senior High Schools in Makassar. They are AthirahSenior High School, KristenSenior High School, FraterSenior High School, Katholik Senior High School, and Cenderawasih Senior High School. Meanwhile, the participants have experienced 
learning processes with Japanese language teachers who have taught more than three years with differentJapanese proficiency levels. However, they have received trainings of Japanese teaching method conducted by The Japan Foundation in Jakarta.

\subsection{Data Collection}

The data are collected through the structured interviews. The main topic is a cooperative learning from the perspectives of Japanese language teachers by implementing the cooperative learningtogether with the teaching activities, problems,techniques, facilities, and six important elements in cooperative learning.In this research, the teachers are required to answer open ended questions. All conversations are recorded with OPPO F1s mobile phone, and then transcribed. The data taken from their conversation tape scripts analyzed based on problem statements.

\section{Research Findings}

\subsection{Japanese Language Teachers' Attitudes Toward the Cooperative Learning}

The data resulted from the interviews offiveJapanese language teachers indicate that basically,they have implemented teaching by conducting group discussionsalthough they have never heard the termof cooperative learning before. They have already knowncooperative learning in group discussions from traditional perspectives which normally mean working together to solvethe grammatical pattern practices. Three teachersare taken as samples coming from Private Senior High Schools: SMU Athirah(participant 1), SMU Kristen (participant 2) and SMU Muhammadiyah (participant 3)stating that they have frequently encouraged the students to implement group discussionsfor every topic ineach lesson. Meanwhile, the other two teachers come from SMUKatholikCenderawasih (participant4) statingthat theyless frequently create the atmospheres of group discussionsin the classroom, and the other one isfrom SMU Frater (participant 5) stating that group discussion is only conducted once a month.

Participant 4 strongly suggests that the implementation of group discussions does not work well as the classroom is difficult to manage, too many noises,some passive students, while those attentive studentscould not concentrate well.Since the teacherswere unable to handle the group discussions, s/he lets the students do the tasks individually, and select one student to see whether they could answer certain questions as instructed.

Participant 1, 3, and5 state that each group discussion consists of three to five students, while participant 5 states thatthe group discussion tends to be in pair-work which means that a group consisting of two students works together to accomplish the task.

In dividing the group, participant 1,2,3, and 5 dominate the decision makingin a group formation. The students feel that the teachersareconsidered much wiserto determinethe group formation;the teachersareconsidered more neutral and able to manage the group. The teachers tend to include one smart student to help the group. In facts, the distribution of smart students is proportionally divided.

Participant 1, 3, and 5 allocate 90 minutes for each lesson(two sessions per meeting). At the beginning of the meeting, three participants explain the grammatical rules including practicesapproximately foran hour, while the group discussion lasted only for 15 minutes. At the end of each discussion, the students are frequently assigned to prepare a small group presentation. Unfortunately, the undertaken steps are not well organized that teacher-student 
gapsfrequently occur. During interviews, the participants admitted ofgiving to many grammar explanations and exercises rather than having interactive or communicative activities.

\subsection{Strengthsand Weaknesses of Cooperative Learning Implementation Based on Teachers'Perspectives}

Based on the data obtained from the interviews ofthose five Japanese language teachers, three participants have implemented group discussions, and mentioned the strengths ofgroup discussions: 1) Students may recognize each other better although the Japanese language class consists of students coming from different classes and majors (Natural Science and Social Science). 2) Because of working together, the studentsmay faster accomplish each task given. Two teachers state that their students prefer doing their tasks in the classroom rather than at home although they are allowed do so in groups.It seems that when students try to complete their work in group at one student' house, some students make various excuses, such as having too many assignments or they do not want to come home lateat night as their parents are worried thatthey may call the school to make sure that they really do their assignment in group together at home. 3) Students have their own roles to make various contributions to their group discussion. 4) Students with better skill levelmay provide motivation to those with below the average skill level that they may work together to accomplish their tasks to show that everybody in the group has important roles. 5) Students are trained to do their work together. 6) By working together in group they are trained to appreciate each other and avoid for being selfish. 7) When the students made presentations on Japanese Cultures, the teachersmay obtain new information from those presentations. 8) Lack of facilities or equipment, such as video tapes and LCD projectors may not support the cooperative learning activities. 9) The teachers find that the teaching aids, such ascards of pictures, copies of situations for role plays, and authentic materials such as magazines, brochures, etcmay help the students.

However, teachers still find problems inhibiting the cooperative learning, such as 1) Whenthe topics are on Japanese Cultures, the teachers find some difficulties on how to handle various resources the students obtain from internetas the teachers have to make sure which information is accurate or reliable. 2) Bothteachers and students areuneasily to find books on Japanese Cultures translated into Indonesian Language, 3) When the students deal with the topicson Japanese Cultures, they seem to be not focusingon what is being discussed and they rarely ask many questions, 4) To motivate the students for paying more attention, the teachers tend to threaten the students with the consequence of getting no scores if they do not participate in the group discussion. However, the teachers still cannot facilitate or control the students to actively engage in group discussion without force, 5) The teachers rely heavily on grammatical practices from books with few dialog practices, and poorly develop the authentic materials used in more natural situations, 6) The teachers are still unable to distinguish group discussion frompeer collaborative learning, 7) The teachers dominate the classroom activities and tend to give explanatory guidance rather than to encourage the students to be more interactive, 8) The allocated time is not well managedwhenconductingthe collaborative learning, because sometimes there are some external interrupting factors, suchas time reduction due to the intensive programs which are not related tothe Japanese language lesson taught in the classroom, 9) The scoring management does not clearly reflect the cooperative learningscores based on processes rather than on results, 10) Teachers are still unable to optimize their efforts to motivate the students to activelyengage in completing their tasks in the classroom. 


\subsection{The implementation ofCooperative Learning in theClassroom forJapanese as Foreign Language}

Based on the students'group discussion, participant 1 tends to focus on finding the meaning of vocabularies they have learnt from the Sakura book organized based on topics (the hand book recently used by SMU Athirah). The students conductthe discussion after watching the video played by the teachers taken from some parts of Sakura book. Meanwhile, the group discussion may determine their own roles; the students play their roles based on their interest or preference.For example, those who are not good or not confident at speaking may write for the group while the others engaged in group discussion. As each discussion is over, the students perform their presentations about the vocabularies and meanings they have discussed. During the presentations, the teachers scored them based on their active participation during the presentation; group discussion, as well as the presentation results.

Participant 2 implements group discussion focusing on the Japanese Cultures instead of the language itself. In this case, the students feel free to explore the topics on Japanese cultures from internet. By using mobile phones or gadgets equipped with Android operation systems, they may access information on Japanese Cultures more efficiently. After the discussion, the students performtheir presentations by showing posters related to the Japanese Culturesbased on the previously discussed topics.

Participant 3 states that the formation of group discussion is to encourage students to accomplish their grammatical pattern practices contained in the Sakura course book. If the students cannot comprehend or find difficulties to answer the questions, they may ask the teacher for help.

Meanwhile, participant 5 suggests that group discussion should be conducted in pairs as the instructions contained in the Sakura book states that the activities made in pairs are more preferable. After the discussion, the students practice the dialogscontained in the Sakura book in pairs in front of the class.

\section{Conclusions}

Based on the discussions above, it can be concluded that cooperative learning is still not yet popular among those five Private Senior High Schools in Makassar. Participants tend to view group discussions with traditional perspectives focusing on working together incompleting the grammatical pattern practices instead of motivating students to be actively engaged in group discussion by using the interesting and authentic topics. The teachers implement group discussion conventionally that they fail to realize their roles in the classroom. They do not teach studentsin appropriate discussion procedures or strategies. Cooperative learning which is conventionally implemented is not relevant with the modern perspective as teachingis intended to achieve the communicative competence.

The authors only conduct a research on cooperative learning to five Japanese language teachers coming from five different Private Senior High Schoolsin Makassar. The collected data are still very limited to those five teachers that the researchersmay not generalize the results. However, the research on cooperative learning may be viewed from different perspectivesand developed withthe other aspects, such asmotivation, strategy, and etc. 


\section{References}

[1]Permendiknas, "Kurikulum 2013," no. 9, 2014.

[2]M. Azizinezhad, M. Hashemi, and S. Darvishi, "Application of cooperative learning in EFL classes to enhance the students ' language learning," Procedia - Soc. Behav. Sci., vol. 93, pp. 138-141, 2013.

[3]E. Bayram, "Implementing cooperative learning in the language classroom : opinions of Turkish teachers of English," vol. 70, pp. 1852-1859, 2013.

[4]R. Slavin, An introduction to cooperative learning research. 1985.

[5]D. C. Mercer and R. A. Mercer, Teaching Students with Learning Problems, 8th Edition | Pearson. Pearson, 2011.

[6]S. Kagan and M. Kagan, Why Do We Need Cooperative Learning? 2009.

[7]E. Akdemir and A. Arslan, "From Past to Present : Trend Analysis of Cooperative Learning Studies," vol. 55, pp. 212-217, 2012.

[8]W. Sanjaya and W. Sanjaya, "Strategi pembelajaran berorientasi standar proses Pendidik, vol. 2008, no. 2008, pp. 1-99, 2008.

[9]D. W. Johnson, R. T. Johnson, C. Learning, D. W. Johnson, and R. T. Johnson, “Cooperative Learning", p. 34.

[10]H. Zhou, "Enhancing Non-English Majorsâ $€^{\mathrm{TM}}$ EFL Motivation through Cooperative Learning," Procedia Environ. Sci., vol. 12, pp. 1317-1323, 2012.

[11]M. Azizan, N. Mellon, R. Ramli, and S. Yusup, "Improving teamwork skills and enhancing deep learning via development of board game using cooperative learning method in Reaction Engineering course," 2018.

[12]J. Antonio Prieto Saborit, J. Fern andez-Río, J. Antonio Cecchini Estrada, A. M. endez-Gim enez, and D. M. endez Alonso, "Teachers' attitude and perception towards cooperative learning implementation: Influence of continuing training," 2016. 